\title{
Educação Ambiental: refletindo sobre a relação criança e natureza na Educação Infantil
}

\author{
Carolina Shimomura Spinelli* \\ Jucilaine Zucco** \\ Juliana da Silva Euzébio**
}

\begin{abstract}
Resumo:
Este texto apresenta o projeto de extensão "Educação Ambiental: refletindo sobre a relação criança e natureza na Educação Infantil" do Núcleo de Desenvolvimento Infantil (NDI) da Universidade Federal de Santa Catarina (UFSC). Este projeto de extensão vem há mais de 10 anos realizando diversas ações voltadas para a relação da criança com a natureza. Possui uma perspectiva histórico-cultural que tem como fundamento a compreensão de que o homem ao transformar a natureza a fim de atender às suas necessidades transforma a si próprio, se humaniza. O projeto almeja a ampliação dos conhecimentos das crianças, de professores e de técnicos do NDI. E se constitui como campo de pesquisa, atuando sobre a formação profissional de acadêmicos, bem como sobre a formação da comunidade externa e de profissionais de outras instituições. Deste modo, articulando as ações de ensino, pesquisa e extensão.
\end{abstract}

\section{Palavras-chave:}

Criança. Educação Infantil. Educação Ambiental.

\begin{abstract}
:
This text presents the extension project "Environmental Education: reflecting on the relationship between child and nature in Early Childhood Education" from the Child Development Center (NDI) of the Federal University of Santa Catarina (UFSC). This extension project has been carrying out several actions for more than 10 years focused on the child's relationship with nature. It has a historical-cultural perspective that is based on the understanding that man, when transforming nature in order to meet his needs, transforms himself, becomes humanized. The project aims to expand the knowledge of children, teachers and NDI technicians. And it constitutes itself as a research field, acting on the professional training of academics, as well as on the training of the external community and professionals from other institutions. In this way, articulating teaching, research and extension actions.
\end{abstract}

\section{Keywords:}

Child. Early Childhood Education. Environmental Education.

\footnotetext{
* Mestre em educação pela Universidade Federal de Santa Catarina, professora de Educação Infantil no NDI/CED/UFSC. E-mail: carolsspinelli@yahoo.com.br. ORCID iD: http://orcid.org/0000-0003-2327-578X.

** Mestre em Educação pela Universidade Federal de Santa Catarina, professora de Educação Infantil no NDI/CED/UFSC. E-mail:jucilaine@hotmail.com. ORCID iD: http://orcid.org/0000-0002-1975-8685.

*** Mestre em Educação pela Universidade Federal de Santa Catarina, professora de Educação Infantil no NDI/CED/UFSC. E-mail: juliana.euzebio@ufsc.br. ORCID iD: http://orcid.org/0000-0002-8907-0907.
} 


\section{Introdução}

Nesse relato de experiência buscamos apresentar algumas das práticas educativas desenvolvidas pelo projeto de extensão "Educação Ambiental: refletindo sobre a relação criança e natureza na Educação Infantil”. Tais práticas são pautadas numa perspectiva histórico-cultural (tendo como ponto de partida a relação do homem com a natureza) e se materializam em conhecimentos que buscam contribuir para a construção da responsabilidade socioambiental e à emancipação humana. O projeto integra a comunidade escolar do Núcleo de Desenvolvimento Infantil (NDI), o Centro de Ciências da Educação (CED) da Universidade Federal de Santa Catarina (UFSC) e a comunidade externa à UFSC. E tem como principais objetivos: o foco nos processos de preservação da natureza, o desenvolvimento sustentável e, simultaneamente, a uma educação estética e crítica em relação ao meio ambiente.

Desse modo, apresentamos a seguir uma breve contextualização sobre o NDI e o projeto de extensão de Educação Ambiental. Na sequência indicamos os desdobramentos do projeto para o ensino das crianças na Educação Infantil e as contribuições para a comunidade interna e externa ao NDI.

\section{Contextualização do Núcleo de Desenvolvimento Infantil (NDI)}

O NDI, criado em 8 de maio de 1980, constitui-se atualmente como uma escola de Educação Infantil, vinculada ao CED/UFSC, reconhecida como Colégio de Aplicação desde o ano de 2013. Atualmente, o NDI assume sua função acadêmica por meio do ensino, da pesquisa e da extensão ${ }^{1}$.

Em relação ao ensino, o NDI atende cerca de 200 crianças, na faixa etária de 3 meses a 5 anos e 11 meses, divididas em 13 grupos, nos turnos matutino e vespertino. O ingresso das crianças acontece por meio de sorteio público, com reserva de vagas para as crianças com deficiência.

As pesquisas desenvolvidas articulam-se aos Programas de Pós-Graduação da Universidade Federal de Santa Catarina, por meio de grupos de pesquisas e também são realizadas pesquisas internas sobre as práticas desenvolvidas nesse núcleo.

Na extensão, o NDI desenvolveu inúmeros projetos ao longo dos anos, participando efetivamente na formação de professores do Estado, na formação de acadêmicos de vários cursos. Deste modo, o NDI é um campo privilegiado de estágio, recebendo semestralmente mais de 20 estagiários que desenvolvem seus estágios acadêmicos obrigatórios. São oriundos de diversos cursos da UFSC e de outras universidades prioritariamente públicas, tais como: Pedagogia, Educação Física, Fonoaudiologia, Artes Cênicas, Música, Design, Biologia e Letras, etc.

\section{Conhecendo o projeto de extensão}

O projeto de Educação Ambiental do NDI, atualmente intitulado "Educação Ambiental: refletindo sobre a relação criança e natureza na Educação Infantil”, iniciou suas atividades no ano de 1995, articulado com o curso de Agronomia da UFSC.

Nas suas atividades iniciais o projeto desenvolvia suas ações com as crianças do Núcleo e seus respectivos professores. A partir do ano de 2002, o projeto de Educação Ambiental foi redimensionado, sendo direcionado também às instituições de Educação Infantil da Rede Pública Municipal, abrangendo, a formação de professores.

Ressalta-se que, no desenvolvimento de experiências sobre Educação Ambiental e, sobretudo, pelo envolvimento dos profissionais do NDI e a inserção de um educador ambiental, esse projeto foi tomando

1. Para maiores informações, acesse o site do núcleo. Disponível em: https://ndi.ufsc.br/. Acesso em: 12 jan. 2020. 
corpo e ganhando maior visibilidade no interior da instituição. Assim, a partir de 2013, atingiu um importante patamar, tornando-se um projeto institucional e articulando-se aos projetos pedagógicos anuais e aos planejamentos dos professores.

O projeto foi fundamentado na teoria histórico-cultural e na proposta curricular do NDI (2014), que entende que o desenvolvimento humano se dá, principalmente, pela relação que cada sujeito constitui com os elementos da cultura e da sociedade em que está inserido e com os outros sujeitos mais experientes. Conforme esses estudos,

[...] as aquisições do desenvolvimento histórico das aptidões humanas não são simplesmente dadas aos homens nos fenômenos objetivos da cultura material e espiritual que os encarnam, mas estão aí apenas postas. Para se apropriar destes resultados, para fazer deles as suas aptidões, "os órgãos da sua individualidade", a criança, o ser humano, deve entrar em relação com os fenômenos do mundo circundante através doutros homens, isto é, num processo de comunicação com eles. Assim, a criança aprende a atividade adequada. Pela sua função, este processo é, portanto, um processo de educação. (LEONTIEV, 1978, p. 272).

A partir de tais premissas, o projeto sistematizou alguns princípios que passaram a nortear as ações pedagógicas relacionadas à Educação Ambiental como um componente essencial da formação humana, fundamental no processo educativo de todas as crianças.

\section{Desdobramentos do projeto para o ensino das crianças}

O projeto de extensão, já apresentado acima, teve como objetivo aprofundar o estudo da relação entre criança e natureza, pautando suas ações e reflexões sob a ótica da perspectiva materialista histórica, ou seja, entendendo que a existência humana não é dada naturalmente, mas sim, é produzida pelo conjunto dos homens, social e historicamente, numa relação de dependência com a natureza e também de transformação da mesma em busca de sua própria subsistência.

Em suma, para se humanizar, o homem necessita se apropriar do conjunto das objetivações humanas e a escola e os processos educativos se constituem numa das principais formas de sistematizar os conhecimentos elaborados historicamente. Nesse sentido, conhecer as condições adequadas para aprendizagem "é condição necessária para a organização intencional das condições materiais de vida e educação que permitam a apropriação das máximas qualidades humanas por cada criança na educação infantil” (MELLO, 2007, p. 89).

Neste sentido, assumir essa perspectiva pedagógica na atividade educativa significa ter presente o modo como a sociedade atual está estruturada, implica, desde a Educação Infantil, sistematizar esse legado de conhecimentos para a apropriação das objetivações humanas nas suas formas mais desenvolvidas (representadas pelos conceitos científicos), expressa ainda, o desenvolvimento da consciência crítica no que se refere às relações e ações humanas no meio ambiente.

A organização das atividades educativas foi planejada conjuntamente, entre os membros do projeto e as professoras do Núcleo e articuladas aos projetos de ensino de cada turma. Estas, buscaram incorporar no planejamento pedagógico as atividades educativas deste projeto, a fim de desenvolver conhecimentos, consciência e sustentabilidade numa relação direta com a natureza e com as crianças. Portanto, o relato a seguir visa dar uma pequena explanação da grande experiência vivida e apreendida com as crianças na relação com o espaço do NDI e da Universidade. 


\section{Descrição das atividades realizadas}

\section{Reciclagem de papel}

A coleta seletiva está distante de ser universalizada e os índices de reciclagem são bastante incipientes. Sabe-se, também, que o papel, nas mais variadas formas (papelão, embalagens, jornais, revistas, papel branco, colorido, entre outras variações) é um produto bastante utilizado no cotidiano. Produzido a partir da celulose de determinados tipos de árvores, ao reciclarmos ou usarmos papel reciclado, contribuímos com o meio ambiente evitando que árvores sejam cortadas, bem como, reduzindo a quantidade de materiais descartados. O intuito dessa proposta foi suscitar questões sobre a importância da reciclagem e as consequências que a falta dela gera ao meio ambiente.

Assim, essa atividade consistiu-se em envolver as crianças no processo de separação dos papéis utilizados, colocando-os na coletora e, posteriormente, realizando as etapas da reciclagem. Cada sala no NDI possui uma coletora de papel destinada para a reciclagem. A atividade é desenvolvida em etapas. Na primeira etapa, a produção industrial de papel é abordada a partir do vídeo "De Onde Vem o Papel?"”. $\mathrm{Na}$ segunda etapa, realiza-se a retirada do papel das coletoras e as crianças o picam para ficar de molho (pelo menos um dia). Na terceira etapa, o papel é triturado no liquidificador formando uma pasta de celulose que será disposta nos bastidores (telas). A 4a etapa é a retirada da folha de papel, já seca. Essa folha de papel poderá ser utilizada para confecção do eco caderno ou outra atividade proposta ${ }^{3}$.

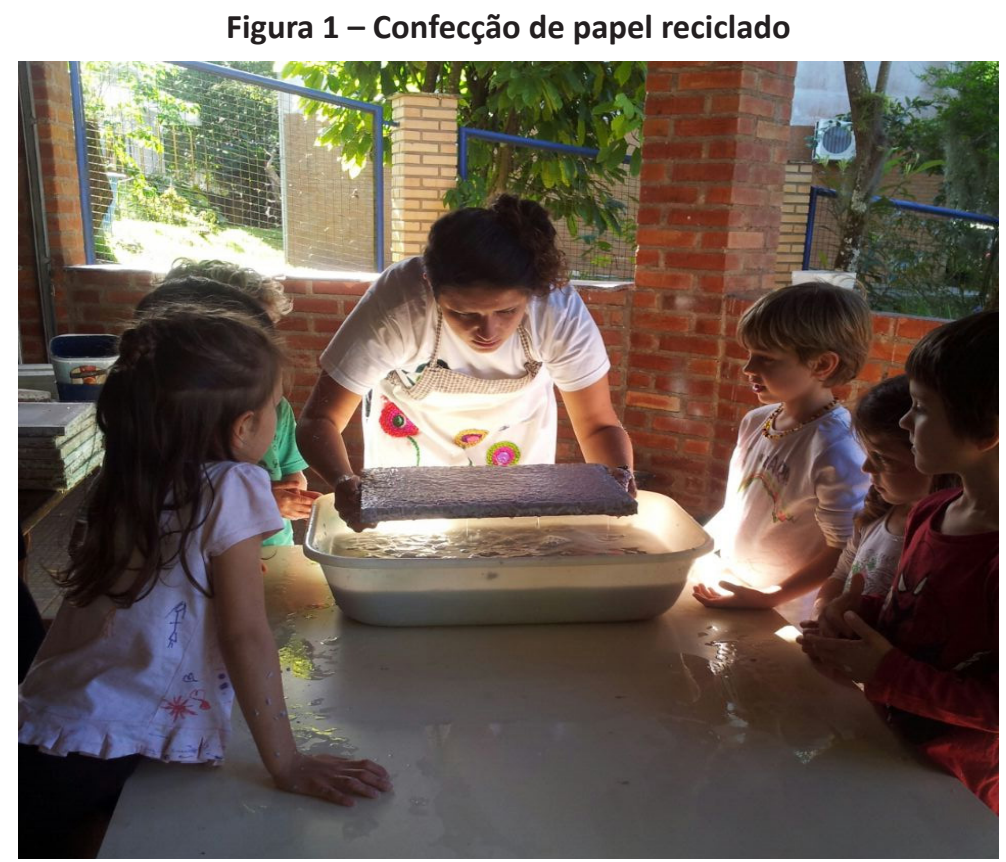

Fonte: Arquivo do projeto de Educação Ambiental do NDI.

\section{Ecocaderno}

A confecção do Ecocaderno ocorre a partir da reutilização de folhas de papel que tenham um de seus lados em branco, provenientes das coletoras de papel e de encadernações obsoletas. Espirais, capas,

2. Disponível em: https://www.youtube.com/watch?v=rjUaQwOVG0k. Acesso em: 8 maio 2018.

3. Todas as imagens aqui utilizadas foram autorizadas pelas famílias das crianças. 
contracapas e folhas são reutilizadas na atividade. As crianças são orientadas em como dobrar e perfurar as folhas de papel e capas. Após isso, com ajuda das bolsistas e da professora, as crianças colocam os espirais, finalizando as encadernações. Os Ecocadernos confeccionados são utilizados de diferentes maneiras pelos grupos: como agenda ou para registro de atividade das crianças (por exemplo desenhos, hipóteses de escrita, entre outros). A folha de papel reciclado, confeccionada através da atividade descrita acima, pode ser usada como capa do eco caderno e personalizada a partir da produção artística das crianças.

Nessa proposta foi possível dialogar com as crianças sobre os 5 Rs: repensar, reduzir, recusar, reutilizar e reciclar, e assim, promover a reflexão sobre os hábitos de consumo, e a forma como utilizamos os recursos oferecidos pela natureza.

\section{Figura 2 - Confecção de Ecocadernos}

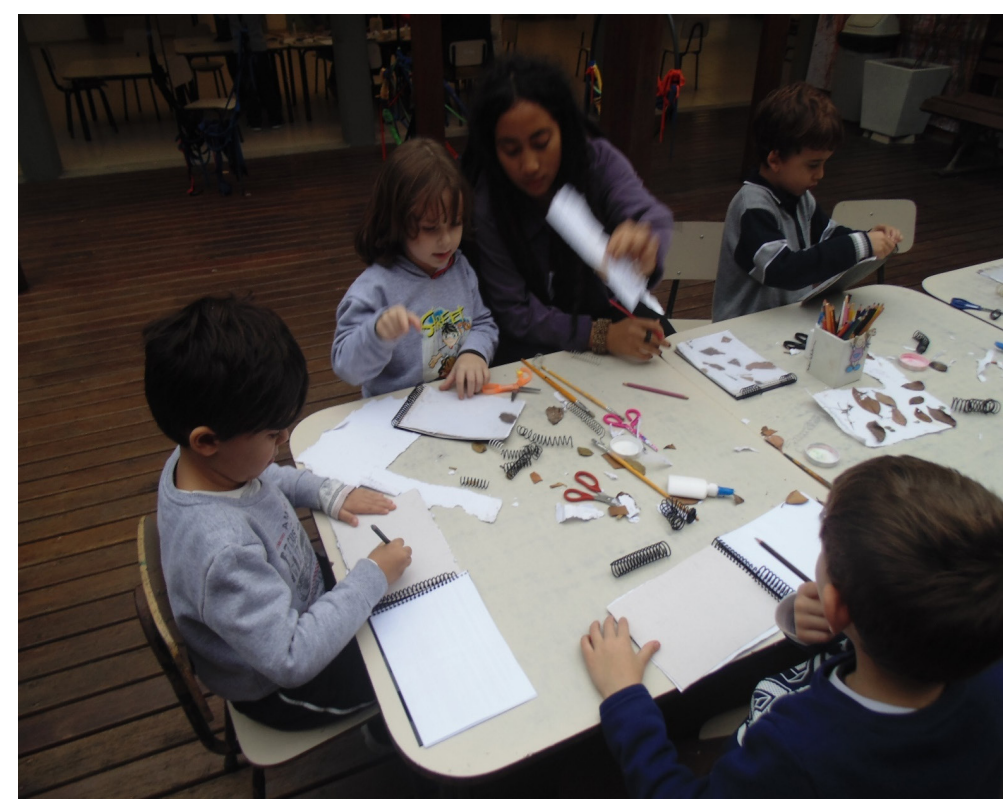

Fonte: Arquivo do projeto de Educação Ambiental do NDI.

\section{Contação de história da minhoca Noca}

Inspirada no livro Minhocas, de autoria de Mariza Konradt de Campos (2015), uma publicação da UFSC, a contação desta história é adaptada para cada grupo, de acordo com a faixa etária e o foco de interesse. A história é apresentada por meio de teatro de fantoche, sendo um momento de interação, ludicidade e conhecimento entre as crianças e a personagem principal - a minhoca Noca. Por meio da atividade imaginária são abordadas algumas curiosidades, características morfológicas, fisiológicas e ecologia desses anelídeos. Em geral, essa atividade tem como objetivo promover a curiosidade e ampliar os conhecimentos sobre os processos de compostagem e confecção do minhocário.

Compreendemos que desde a Educação Infantil, é possível garantir às crianças experiências que promovam situações de aprendizagem em que elas se mobilizem a "apreender, compreender, descobrir e descobrir-se nesse mundo em que vivemos, por meio do ensino de ciências, estamos a formar indivíduos que possuem um pensamento imaginativo, disciplinado e criativo" (ARCE; SILVA; VAROTTO; MIGUEL, 2011, p. 61). Essas experiências, intencionais, planejadas pelo professor, tem como objetivo promover a aprendizagem e o desenvolvimento da criança como sujeito participativo. 


\section{Figura 3 - Contação de história da minhoca Noca para crianças de 0 a 3 anos}

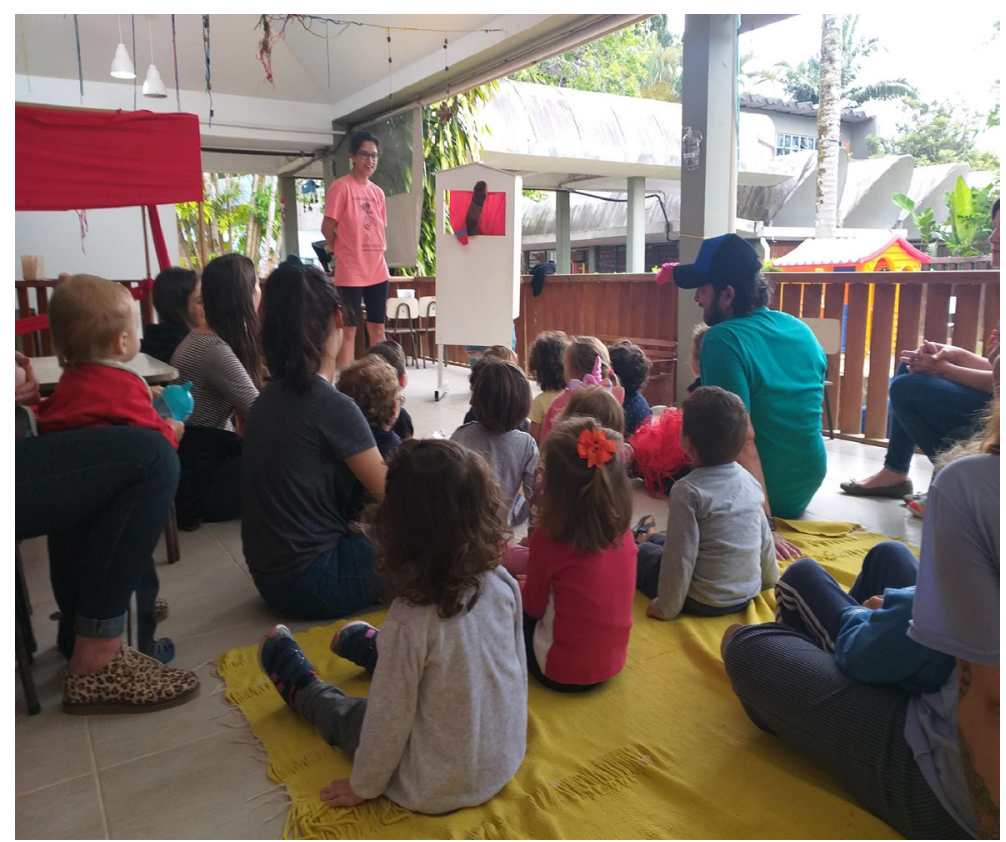

Fonte: Arquivo do projeto de Educação Ambiental do NDI.

\section{Minhocário}

Sabe-se que os resíduos orgânicos, representam cerca de 50\% dos resíduos urbanos gerados no Brasil, podem ser reciclados por meio de processos como a compostagem (em qualquer escala: da doméstica até a industrial). Segundo dados contidos em Compostagem doméstica, comunitária e institucional de resíduos orgânicos: manual de orientação (BRASIL, 2017), a maior parte dos resíduos orgânicos domésticos, são desprezados em aterros sanitários ou lixões, misturados a rejeitos, desperdiçando nutrientes e matéria orgânica que, no ciclo natural, teriam o papel de fertilizar e manter a vida nos solos.

Compreendendo a importância de reduzir os resíduos gerados, assim como, em contribuir para a melhoria de condições de vida e saúde, a MinhoCasa, com finalidade análoga à de uma composteira, possibilita a utilização de maneira eficiente e racional dos resíduos orgânicos para a produção de adubo. Montada com a participação das crianças, semanalmente, sob orientação das bolsistas e/ou professoras do grupo, a MinhoCasa é abastecida com os resíduos orgânicos gerados a partir do lanche e selecionados pelas próprias crianças. Por meio dessa atividade, são abordadas a morfologia, a fisiologia e o papel ecológico das minhocas. Além do adubo, essa técnica de compostagem gera também o biofertilizante líquido, utilizado para nutrir as plantas na rega.

Ao compreender o funcionamento de um minhocário/composteira, as crianças empregam procedimentos que envolvem habilidades de intenção experimental, observação, investigação, formulação de hipóteses, etc., que possibilitam aproximações cada vez mais complexas a campos de conhecimentos e conceitos científicos. As experiências práticas organizadas pelas professoras possibilitam o desenvolvimento de conhecimentos sobre o mundo, ampliando assim o repertório das crianças e construindo bases para novas aprendizagens. 
Figura 4 - Confecção de MinhoCasa

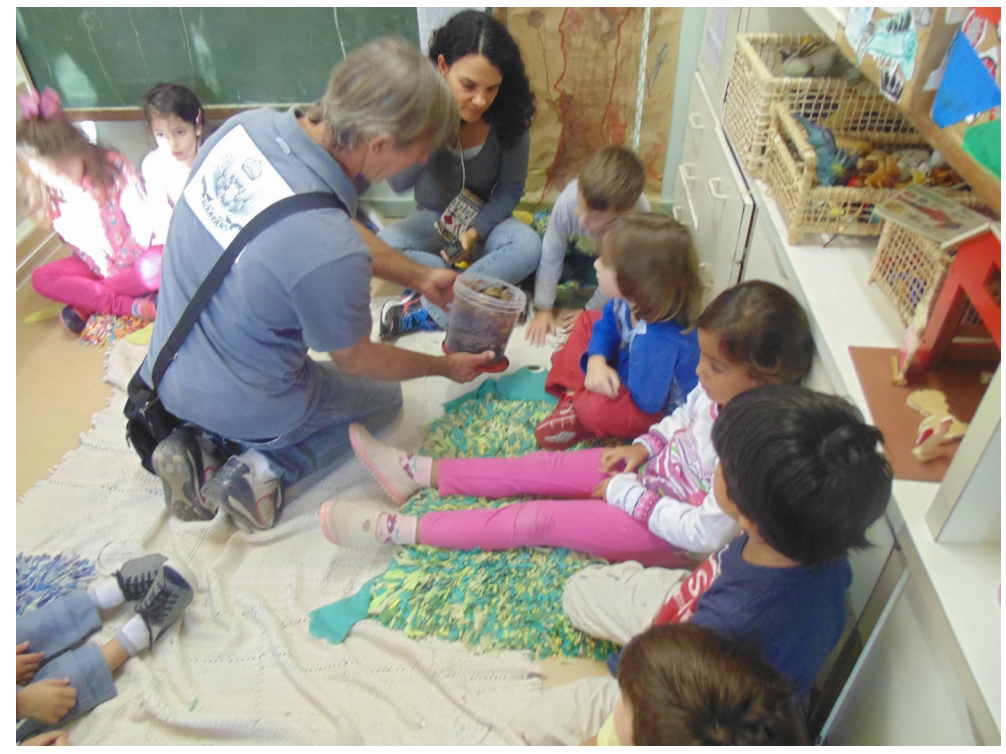

Fonte: Arquivo do projeto de Educação Ambiental do NDI.

\section{A horta: do plantio de sementes ao cultivo de alimentos}

A horta é um grande espaço de aprendizado para as crianças. Neste espaço criam-se diversas possibilidades, em variadas áreas do conhecimento por meio da observação, da ação e da reflexão. A adubação da terra, o plantio e a manutenção das mudas, o reconhecimento e o cuidado de cada espécie permite uma relação direta das crianças com o meio e também permite vivenciar a importância da natureza, dos polinizadores e de uma alimentação saudável. Nesse contexto, as crianças realizam sínteses, generalizações, classificações, e vão desenvolvendo seu nível de compreensão com relação ao meio ambiente.

Essas atividades possibilitam novas experiências para as crianças, ampliando os níveis de combinações com os elementos da realidade, assim, também são propostas que promovem o desenvolvimento da imaginação e da criação e o desenvolvimento da psique. Estas "qualidades humanas que não são naturais, mas precisam ser aprendidas, apropriadas por cada criança por meio de sua atividade no entorno social e natural em situações que são mediadas por parceiros mais experientes” (MELLO, 2007, p. 91).

Figura 5 - Adubando a terra

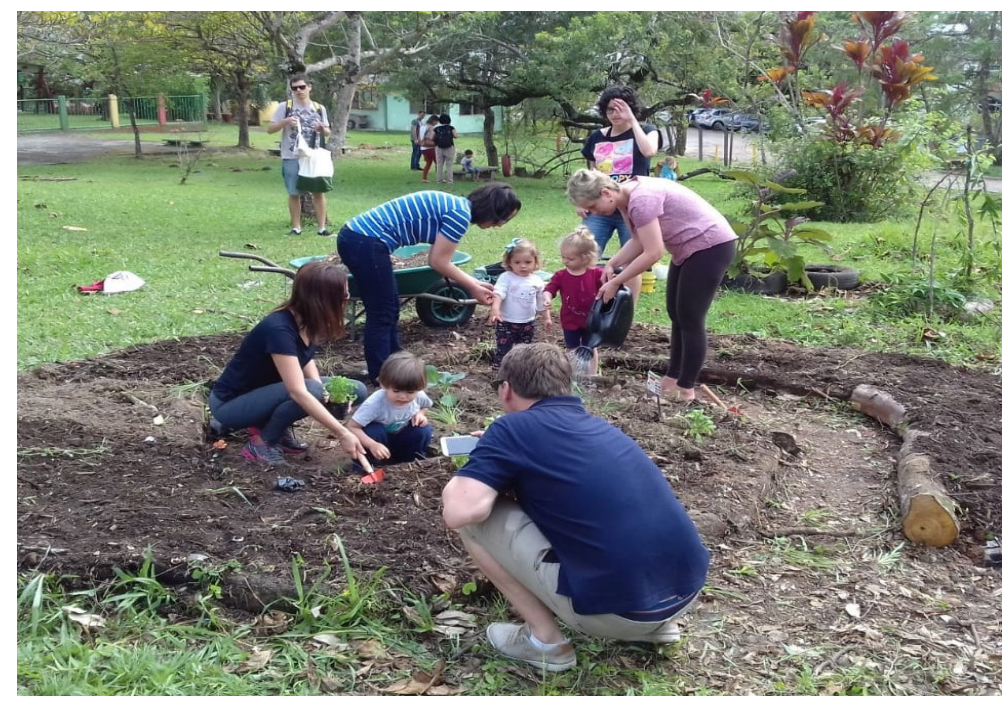

Fonte: Arquivo do projeto de Educação Ambiental do NDI. 
Os momentos de plantio, de contato com a terra e com as plantas, também proporcionam a descoberta e o encantamento nas experiências de observação de seres minúsculos que se escondem na terra, tais como: minhocas, embuás, insetos, aves, etc.

\section{Figura 6 - Plantio de mudas na horta}

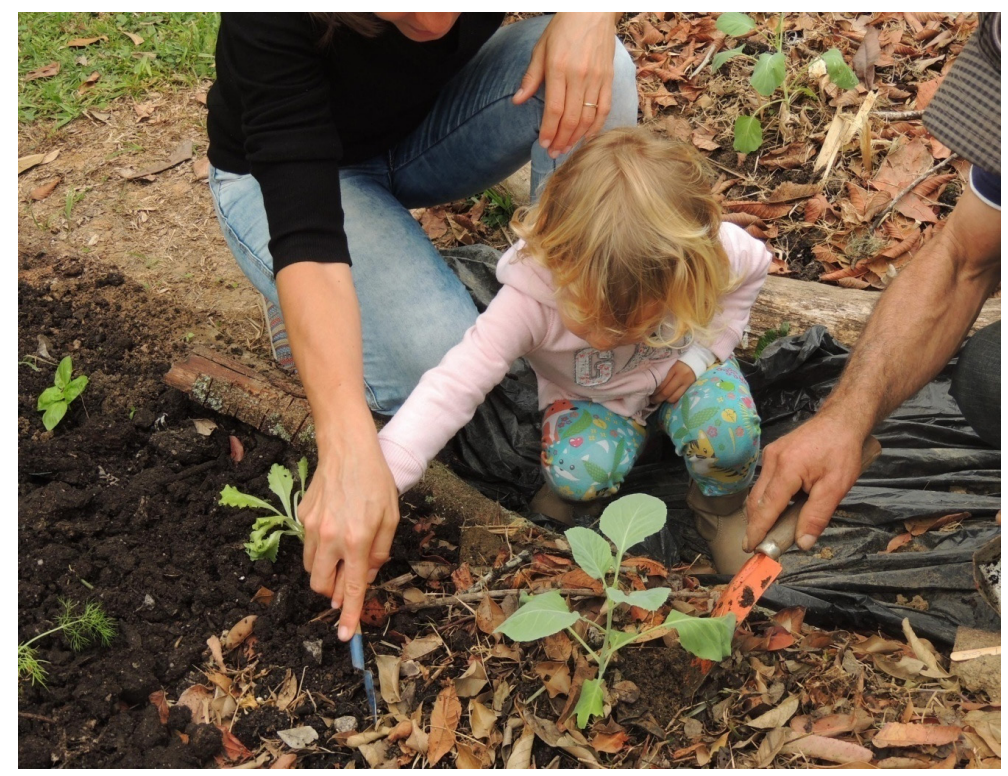

Fonte: Arquivo do projeto de Educação Ambiental do NDI.

Os alimentos e as frutas colhidas foram destinados ao lanche das crianças e às propostas de atividades culinárias, em parceria com o setor de nutrição do NDI. Assim, compreende-se que as crianças desde pequenas, têm capacidade de aprender sobre a origem dos alimentos e de fazer relações com a saúde de seu corpo e seu crescimento. Uma alimentação saudável deve ser promovida e incentivada, como direito das crianças, assim como, os conhecimentos relacionados à relação do homem com a natureza.

Conhecer e entender como os alimentos são produzidos e o que esta produção envolve em termos sociais, econômicos e biológicos é um passo fundamental para a formação de uma atitude mais consciente em relação ao consumo, à promoção da saúde e da sustentabilidade. As vantagens da alimentação orgânica, integral e natural e os problemas associados ao uso de agrotóxicos, bem como os hábitos alimentares e culturais e sua relação com a saúde e bem estar, são alguns dos vários assuntos que podem ser discutidos. (BRASIL, 2017, p. 62).

Desse modo, compreendemos que ensinar Ciências na Educação Infantil é uma tarefa a ser assumida pelos professores, ao organizar intencionalmente experiências diversificadas, que possibilitam acompanhar o processo de aprendizagens e de desenvolvimento e a formação de novas atitudes e valores. 


\section{Figura 7 - Culinária com Plantas Alimentícias Não Convencionais (PANCs) cultivadas na horta}

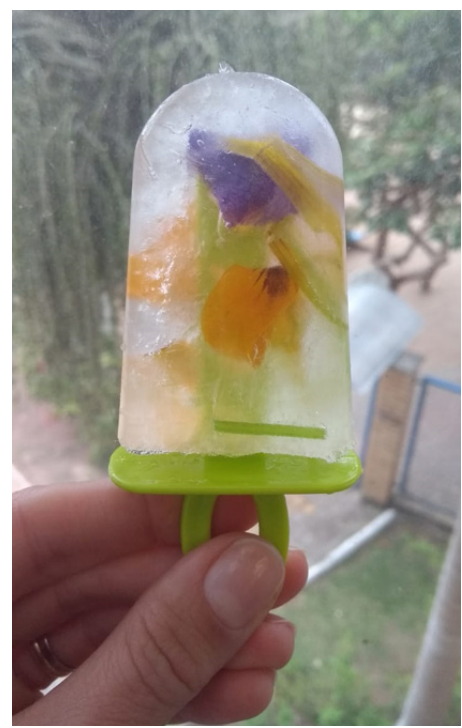

Fonte: Arquivo do projeto de Educação Ambiental do NDI.

\section{Ervas medicinais no "Cantinho da Vovó"}

O espaço denominado "Cantinho da Vovó" abriga diversas plantas medicinais que foram plantadas pelas crianças. A atividade consiste no cuidado e na manutenção desse espaço, além do plantio de novas espécies de plantas medicinais e até algumas alimentícias, tanto pelo método de estaquia como o de sementes.

Na produção de estaquia, por exemplo, colocou-se um galho de manjericão na água e acompanhou-se o processo de enraizamento. Por meio da observação, instigou-se a curiosidade das crianças e o levantamento de hipóteses sobre o nascimento de uma planta, a partir de partes da mesma, e do que ela precisa para crescer saudável. Após essa etapa, foi feito o plantio desta muda na terra.

De acordo com Arce e Silva (2014, p. 87), "ao apontar e questionar, mesmo sem dar explicações avançadas, os professores podem ajudar as crianças a descobrirem uma variedade de objetos e fenômenos que, mais tarde, servirão de subsídios para os futuros conceitos científicos”. Nesta proposição as crianças puderam observar a germinação de uma planta a partir de seu galho e produzir uma nova muda. Nesse processo, elas precisaram assumir uma postura de cuidado em relação às plantas, e também ao começar a compreender como ocorre o desenvolvimento desse ser vivo.

O reconhecimento dos diferentes cheiros, sabores, cores, flores, formatos e usos das plantas medicinais foram abordados e vividos durante todo o ano. O cultivo de plantas medicinais permitiu o preparo de chás para as crianças beberem durante os lanches e também em outras atividades do projeto.

\section{Figura 8 - Plantio de ervas medicinais no "Cantinho da Vovó"}

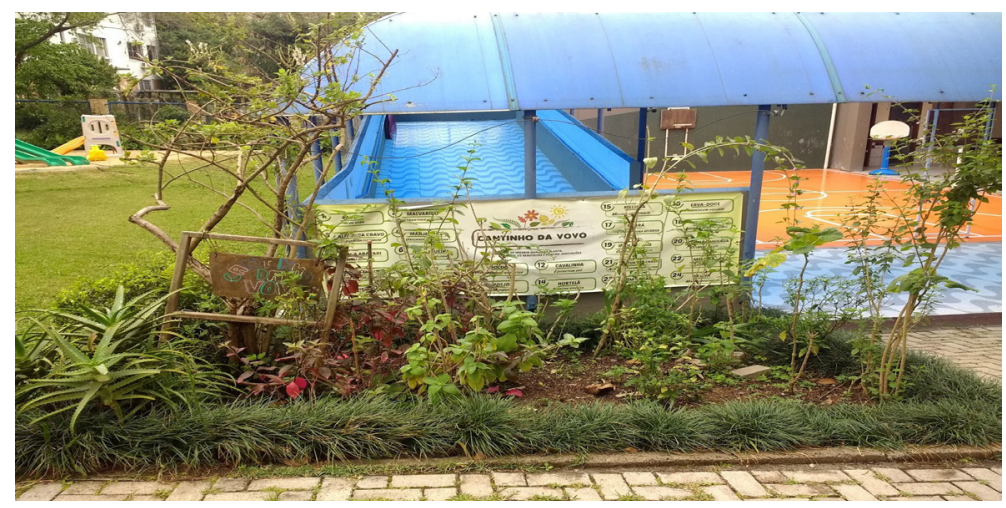

Fonte: Arquivo do projeto de Educação Ambiental do NDI. 


\section{Exposição de animais: anfíbios e répteis}

A exposição de animais (anfíbios e répteis), partindo do pressuposto de que a observação, a exploração, a experimentação, permitem às crianças construírem conhecimentos, teve como objetivo aproximar os conhecimentos práticos aos conteúdos científicos, e ainda, de promover o respeito e o cuidado com os animais que habitam o espaço do NDI. Nesse período as crianças vinham observando, com bastante curiosidade, os lagartos que circulavam nos parques e outros espaços.

Desse modo, tomando o interesse infantil como ponto de partida, buscou-se ampliar o conhecimento das crianças sobre outras espécies que existem nesse espaço, tais como cobras, sapos, lagartixas etc. Em parceria com um dos projetos de extensão do Laboratório de Ecologia de Anfíbios e Répteis (LEAR/ CCB/UFSC), organizou-se, então, uma exposição com exemplares da coleção didática do laboratório ${ }^{4}$. Importante dizer que a própria exposição e a forma de apresentação destes exemplares suscitaram mediações no sentido de esclarecer às crianças as razões daqueles animais estarem lá (fora de seu habitat natural), de como e para que são conservados.

A realização desta atividade possibilitou conhecer melhor a biodiversidade de anfíbios e répteis que habitam o local, bem como, compreender a importância desses animais para o ecossistema, possibilitando o contato direto das crianças com a morfologia e a diversidade de espécies, ressaltando-se, sempre, o respeito e o cuidado por toda a forma de vida e sua importância na natureza. Também foram abordadas as medidas preventivas e de primeiros socorros. Com esta proposta de atividade, foi possível criar situações de aprendizagem a partir do que Arce e Silva (2014) denomina como um processo sistemático de ensino. Nas palavras das autoras esse processo é

[...] capaz de conduzir o olhar da criança para o quê observar e aquilo que está por trás de cada fenômeno ou objeto, estimulando-a a enxergar um horizonte mais amplo. Nesse processo, o trabalho planejado e intencional do professor promove a transformação dos conhecimentos (conceitos) elementares da criança em conhecimentos mais elaborados e complexos. (ARCE; SILVA, 2014, p. 88).

Assim, a Educação Ambiental na Educação Infantil, assume seu papel de promover a apropriação do mundo objetivo.

Figura 9 - Exposição de anfíbios e répteis

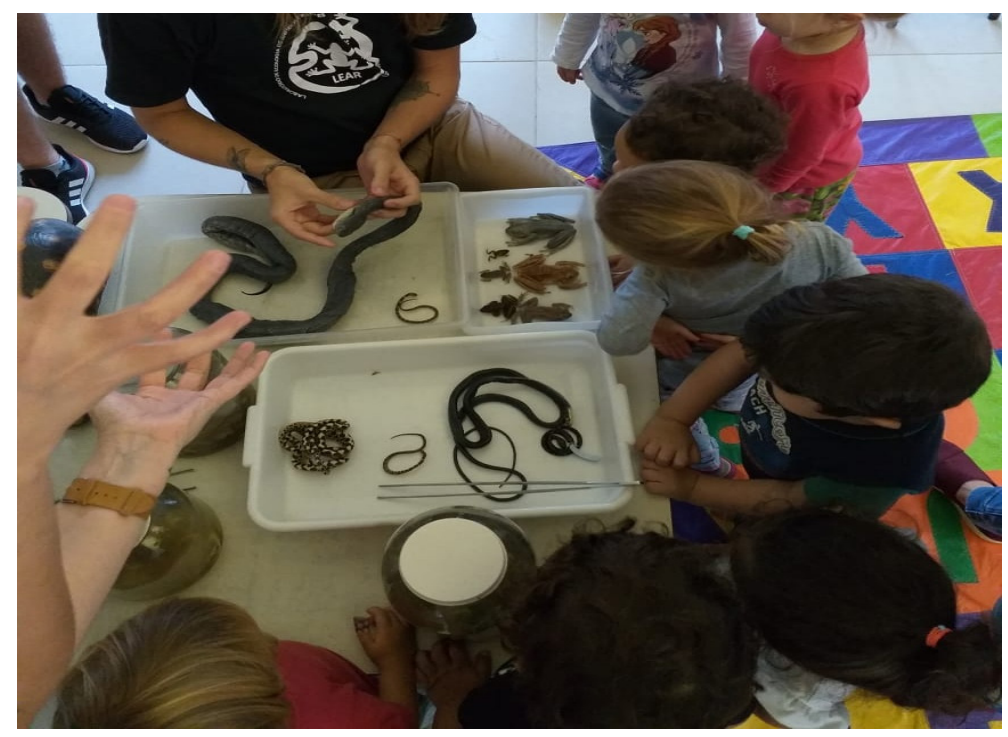

Fonte: Arquivo do projeto de Educação Ambiental do NDI.

4. Mais informações sobre visitas ao laboratório disponíveis em: http://www.herpetologia.ufsc.br/visita/. Acesso em: 20 maio 2019. 


\section{Exposição de maquetes no NDI}

Resultante da parceria entre o projeto de Educação Ambiental e o projeto "Uso sustentável da água no Núcleo de Desenvolvimento Infantil (NDI/UFSC)” foram realizadas 5 exposições. Nestas exposições buscou-se promover a socialização de conhecimentos sobre ecologia e Educação Ambiental entre os estudantes da disciplina "Fundamentos de Ecologia" do curso de Engenharia Ambiental e Sanitária da UFSC e as crianças, as professoras, os funcionários e as famílias do NDI. As maquetes construídas tiveram as seguintes temáticas: ciclo da água; bacias hidrográficas rios/lagos; reuso da água da chuva e reservatório artificial.

Primeiramente, os estudantes foram recepcionados na instituição para uma apresentação do espaço do NDI/CED/UFSC e das especificidades do trabalho na Educação Infantil, bem como, das características do desenvolvimento das crianças. Tal apresentação foi necessária para que os estudantes da disciplina pudessem ter mais elementos para pensar as mediações possíveis de modo a tornar os conhecimentos produzidos mais acessíveis às crianças e adultos do NDI.

Esta atividade culminou com a organização da exposição e apresentação das maquetes elaboradas pelos estudantes da primeira fase do curso de Engenharia Ambiental da UFSC para as crianças, os docentes e os funcionários do NDI. O intuito da mesma foi relacionar os conhecimentos teóricos da referida disciplina à prática, pensando e propondo possibilidades da Educação Ambiental (uso sustentável da água e sua relação com as pessoas) para o trabalho pedagógico com as crianças.

Figura 10 - Exposição de maquetes

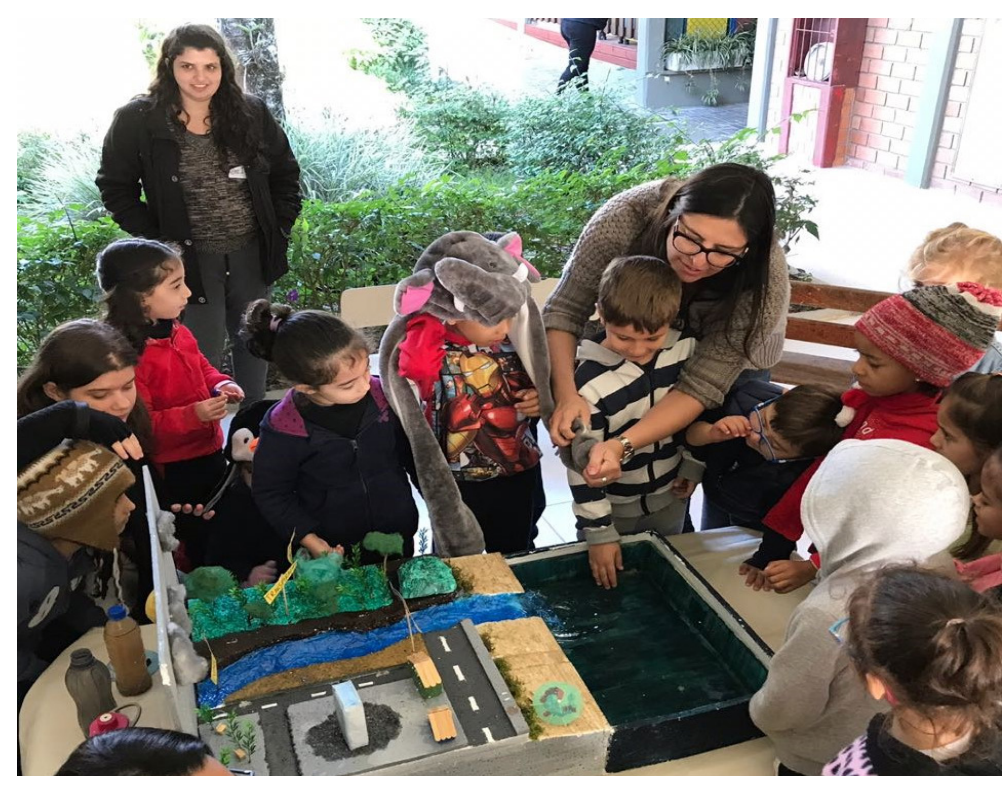

Fonte: Arquivo do projeto de Educação Ambiental do NDI.

\section{NDI Sustentável}

Importante momento de divulgação e de socialização das atividades que são desenvolvidas pelo projeto de Educação Ambiental para a comunidade interna e externa ao NDI, ampliando a compreensão dos envolvidos com relação às práticas sustentáveis e de preservação do meio ambiente.

O NDI Sustentável, realizado desde 2016, em sua 4a edição, buscou promover atividades concernentes ao desenvolvimento sustentável, ao uso racional de recursos naturais e à emancipação humana, integrando a comunidade escolar e a comunidade externa à UFSC. No ano de 2019 foram realizadas diversas atividades artísticas com elementos naturais, inspiradas na EcoArt e Land Art. Concomitantemente, aconteceram brincadeiras ao ar livre a partir do uso de elementos naturais; exposição de minhocário/composteira 
e a IV Feira de Trocas (atividade que visa estimular a economia solidária, incentivando o aproveitamento e reutilização dos objetos, prolongando sua vida útil e reduzindo a geração de resíduos ${ }^{5}$ ).

\section{Figura 11 - Convites das quatro edições do NDI Sustentável}

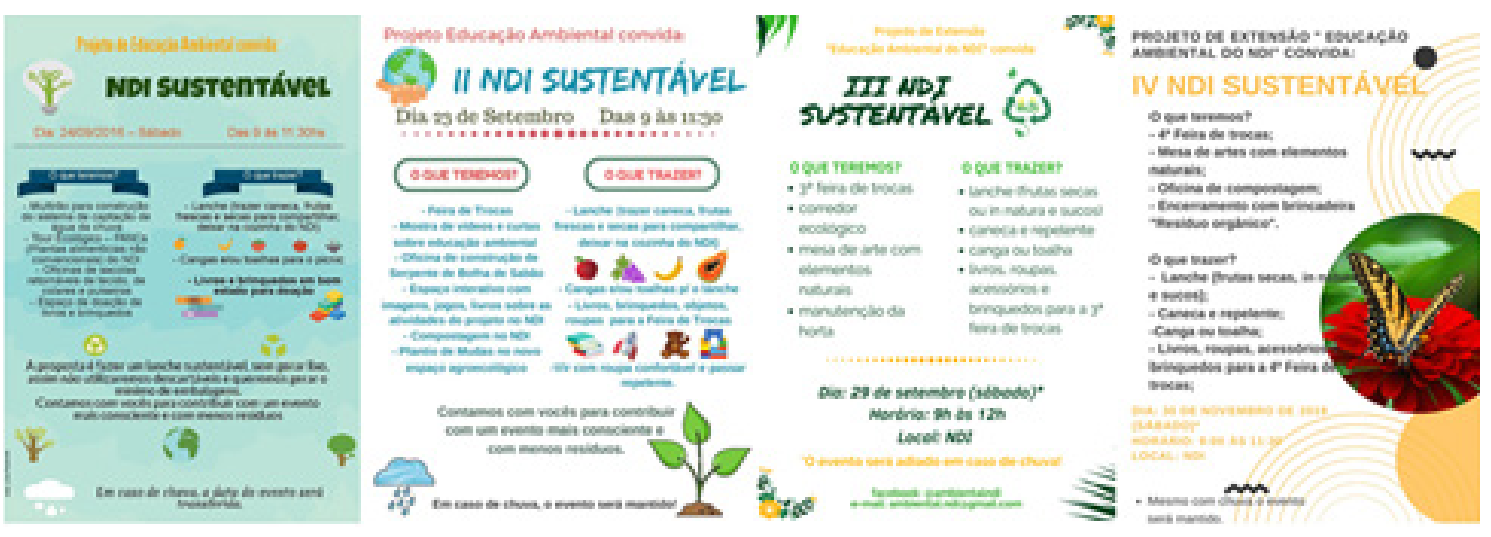

Fonte: Arquivo do projeto de Educação Ambiental do NDI.

\section{Implicações sociais do projeto de extensão}

Pelos dados registrados participam das ações desse projeto, anualmente, cerca de oitocentas pessoas. Somente no NDI, as atividades são desenvolvidas cotidianamente com cerca de duzentas crianças e suas respectivas famílias. Também participam todos os profissionais do NDI, incluindo os estagiários, bem como professores, coordenadores pedagógicos e gestores de diversas instituições de Educação Infantil das redes públicas por meio de visitas monitoradas e oficinas que o NDI oferece sistematicamente.

Compreendemos, portanto, que se trata de um projeto com relevância social e política, ao buscar pela defesa da socialização e apropriação dos conhecimentos historicamente desenvolvidos pelas ciências desde a Educação Infantil e na construção de valores éticos, políticos e estéticos, articulados a uma educação que promova as qualidades humanas e sua relação consciente com a natureza.

\section{Considerações finais}

As atividades apresentadas nesse texto, realizadas pelo projeto de extensão de Educação Ambiental, tiveram o escopo de contribuir para que mais professores possam se fundamentar e guiar as suas práticas pedagógicas no sentido de possibilitar às crianças a exploração do mundo, os conhecimentos sobre as plantas, as sementes, a natureza, num processo de "observar, experimentar, pensar e questionar, chamando sua imaginação, a todo o momento, a participar das descobertas" (ARCE; SILVA, 2014, p. 97). Neste sentido, compreendemos a importância do trabalho do professor, ao planejar e escolher as atividades que serão desenvolvidas com as crianças, guiando o seu olhar, a sua curiosidade e seus questionamentos de acordo com os objetivos que foram pensados e estudados previamente.

Vale destacar que, em consonância com as legislações nacionais referentes à Educação Ambiental, este projeto de extensão procurou discutir as questões ambientais articuladas à compreensão das conjunturas culturais, políticas e econômicas que compõem o cotidiano. O objetivo principal foi propor, planejar,

5. Segundo dados da Associação Brasileira de Empresas de Limpeza Pública e Resíduos Especiais (ABRELPE, 2019), no Panorama dos Resíduos Sólidos no Brasil, edição 2018/2019, das 72,7 milhões de toneladas de Resíduos Sólidos Urbanos (RSU) coletadas no Brasil em 2018, 59,5\% tiveram disposição final adequada e foram encaminhadas para aterros sanitários. Cerca de 40,5\% foram despejados em locais inadequados por 3.001 municípios. Esse percentual diz respeito a 29,5 milhões de toneladas de resíduos que acabaram indo para lixões, gerando danos e degradações ao meio ambiente e à saúde. 
criar atividades concernentes ao desenvolvimento sustentável e à emancipação humana, integrando a comunidade escolar e a comunidade externa à UFSC.

Diante do exposto, parece-nos fundamental reafirmar a necessidade da reflexão dos processos educativos da Educação Infantil, articulados aos conceitos sobre Educação Ambiental e ao desenvolvimento das crianças.

\section{Referências}

ASSOCIAÇÃO BRASILEIRA DE EMPRESAS DE LIMPEZA PÚBLICA E RESÍDUOS (ABRELPE). Panorama dos resíduos sólidos no Brasil 2018/2019. São Paulo: ABRELPE, 2019. Disponível em: http://abrelpe.org.br/panorama/. Acesso em: 10 jul. 2020.

ARCE, Alessandra; SILVA, Débora Alfaro São Martinho da; VAROTTO, Michele; MIGUEL, Carolina Costa. Ensinando Ciências na Educação Infantil. Campinas: Alínea, 2011.

ARCE, Alessandra; SILVA, Débora Alfaro São Martinho da. Ensinar ciência aos pequeninos: a ampliação dos horizontes da criança na descoberta de si e do mundo. In: ARCE, Alessandra (org.). O trabalho pedagógico com crianças de até três anos. Campinas: Alínea, 2014.

BRASIL. Ministério do Meio Ambiente. Compostagem doméstica, comunitária e institucional de resíduos orgânicos: manual de orientação. Brasília, DF: MMA, 2017.

CAMPOS, Mariza Konradt de (org.). Minhocas. Florianópolis: BU/UFSC, 2015.

LEONTIEV, Alexis Nikolaevich. O desenvolvimento do psiquismo. Tradução de Manuel Dias Duarte. Lisboa: Livros Horizonte, 1978.

MELLO, Suely Amaral. Infância e humanização: algumas considerações na perspectiva histórico-cultural. Perspectiva, Florianópolis, v. 25, n. 1, p. 85-104, jan./jun. 2007. Disponível em: https://periodicos.ufsc.br/index.php/perspectiva/ article/view/1630/1371. Acesso em: 4 set. 2019.

NÚCLEO DE DESENVOLVIMENTO INFANTIL (NDI). Proposta Curricular: volume 1. Florianópolis: UFSC/CED/ NDI, 2014. Disponível em: http://ndi.ufsc.br/files/2015/04/Proposta-Crricular-do-NDI.pdf. Acesso em: 12 maio 2020.

Data de submissão: 17/06/2020

Data de aceite: $14 / 07 / 2020$ 